\title{
Psychosocial and Cultural Contributions to Depression in Women: Considerations for Women Midlife and Beyond
}

\author{
Gwendolyn Puryear Keita, PhD
}

\begin{abstract}
BACKGROUND: Women share a greater burden of mood disorders than men and have twice the prevalence rate of depression.

OBJECTIVE: To highlight some of the psychosocial and cultural contributions to depression in women.

SUMMARY: Multiple factors contribute directly or interact to precipitate the onset of depression. Genetics, stress life events, previous history of depression, and cognitive factors have been shown to be significant risk factors for future depression episodes. Life stressors contribute to the onset of depression in both men and women, but particular stressors affect the genders differently, with women identifying more closely with relationship issues, lack of adequate housing, and poverty. Women are also more frequently affected by physical and sexual abuse, which will significantly influence future episodes of depression. Depression does not discriminate on the basis of race. Women of all ethnic groups suffer from depression. However, research indicates that there may be differences in prevalence and treatment-seeking behavior in black Americans, Mexican Americans, and white Americans.
\end{abstract}

CONCLUSION: Many factors contribute to the occurrence of depression. Some of these occurrences may be explained by the changing hormonal milieu, susceptibility after physical or sexual abuse, poverty, housing problems, or loss of a close friend. One of the explanations for the higher rate of depression in women is that women have a greater incidence of first depressive episodes, which often begin during adolescence or young adulthood.

J Manag Care Pharm. 2007;13(9)(suppl S-a):S12-S15

Copyright@ 2007, Academy of Managed Care Pharmacy. All rights reserved.

\section{Author}

GWENDOLYN PURYEAR KEITA, PhD, is executive director, Public Interest Directorate, American Psychological Association, Washington, D.C.

AUTHOR CORRESPONDENCE: Gwendolyn Puryear Keita, PhD, Executive Director, Public Interest Directorate, American Psychological Association, 750 First Street, NE, Washington, DC 20002-4242. Tel.: 202.336.6050; Fax: 202.336.5723; E-mail (assistant):

shouston@apa.org
I dentification and treatment of depression in women represent challenges and unmet needs in medicine. Beginning during adolescence and into early adulthood, women are twice as likely as men to have a depressive episode. ${ }^{1}$ The reasons for this discrepancy are many and complex, but it has been explained by both biological and psychosocial factors. ${ }^{1}$ Women also face life changes not experienced by men, such as pregnancy and postnatal and perimenopausal periods. These appear to be times of increased risk of depression for some women. A first depressive episode sets in motion a chronic course that causes substantial human capital loss for women, prevention and treatment of first episodes of depression should be a primary goal.

\section{Gender Differences in Rates of Depression}

Depression is approximately twice as common in women than it is in men, and the rate differences begin to appear during early adolescence. ${ }^{2}$ In childhood, there are similar levels of depressive disorders and depressive symptoms. By the age of 12 , girls' rates of depressive disorders and depressive symptoms increase, while boys' rates increase only slightly or not at all. By the age of 18, a consistent female: male ratio of $2: 1$ is seen in the United States. One of the possible reasons for differences in depression prevalence rates between the genders is that the single highest risk factor for subsequent depression episodes is a history of depressive episodes, and that girls have a greater number of first-onset episodes than boys do. Additionally, evidence demonstrates a genetic role in vulnerability to depression, and still more evidence suggests that this genetic vulnerability is more pronounced in women than in men. ${ }^{3-5}$

\section{Hypotheses to Explain Gender Differences in Depression}

\section{Stressful Life Events}

Data are mixed on whether women experience more adverse life events. One study, investigating the differences in stressful life events (SLEs) contributing to depressive symptoms in both sexes, found no evidence for an overall gender difference in sensitivity to the depressogenic effects of SLEs. ${ }^{6}$ However, life events considered stressful differed between the sexes. Men consistently reported significantly higher rates of occurrence of 4 SLEs: job loss, legal problems, robbery, and work problems. Women consistently reported housing problems, loss of a confidant, proximal relationship problems, and illness of an individual in their distal network as SLEs. Discrimination, particularly race discrimination, is another chronic stressor associated with depression in women's lives. ${ }^{7.8}$ While data are mixed on differences in exposure to SLEs, women are more likely to experience major depression in the wake of an SLE. ${ }^{9}$ 


\section{Physical and Sexual Abuse}

Compared with men, women more frequently experience certain kinds of negative life events, such as physical and sexual abuse, poverty, and gender discrimination. In women, physical and sexual abuses are potent risk factors for depression (Table). The lifetime prevalence of depression is almost double for victims of completed rape in childhood (52\%) than it is for nonvictimized women $(27 \%){ }^{10}$ The mean prevalence rate of depression among battered women is $48 \% .{ }^{11}$ Childhood physical abuse is a strong predictor of adult depression in all ethnic groups after controlling for background characteristics that are risk factors for both abuse and depression. ${ }^{12}$ Additionally, suicidality (recurrent thoughts of death or suicidal ideation and plans, and attempts or gestures of self-harm with death as a possible result) is strongly linked to a history of abuse..$^{13,14}$

\section{Poverty}

Poverty is a chronic stressor highly correlated with depression. Association between socioeconomic status and depression exists at all levels of the socioeconomic status hierarchy. Poverty increases risk of acute stressors, which include exposure to crime, violence, physical or sexual assault, and illness and death of children. ${ }^{15}$

\section{Integrated Cognitive Model of Depression}

Many models have attempted to explain depression pathophysiology. The integrated cognitive model of depression postulates that the interaction between negative life events (e.g., physical and/or sexual abuse, unrelenting poverty, and discrimination) and negative cognitive style (e.g., excessive dependency on others, being a ruminator), genetic vulnerability, hormonal changes, and hypothalamic-pituitary-adrenal axis dysregulation could independently contribute to women's higher rates of depression. ${ }^{16,17}$ However, the factors likely interact in complex ways to produce depression, particularly in women. This model helps to explain why depression has a cyclical pattern in some women, particularly in situations of rumination or appalling past life experiences. Though depression has various triggers, once it is activated, the symptoms are similar regardless of the cause. According to this model, when the symptoms are allowed to cycle automatically, the state can maintain itself for a period of time.

\section{Women's Life Stages and Depression}

It is hypothesized that changes in hormone levels in women are a contributing factor for the differences in depression prevalence across a woman's lifetime. ${ }^{18,19}$ A dramatic shift in depression prevalence is apparent during adolescence in girls sometime between the ages of 10 and 15 years. During early adulthood, depression becomes most prevalent, with a typical onset between the second and third decades. Women of childbearing age are at heightened risk of experiencing a depressive episode. Approximately

\section{TABLE}

Socioeconomic and Biological Reasons to Explain Depression in Women W $^{51,18,33}$

- Sexual or physical assault or ongoing abuse

- Unrelenting poverty

- Discrimination

- Negative cognitive style

- Excessive dependency on others

- Rumination

- Genetic vulnerabilities

- Hormonal changes

- Hypothalamic-pituitary-adrenal axis dysregulation

$9 \%$ of pregnant women and $13 \%$ of postpartum women experience major depressive disorder. ${ }^{20-22}$ Yet the risk of depressive recurrence increases to $25 \%$ for women with previous episodes of postpartum depression. ${ }^{23}$

The transition from regular menstrual cycling to complete cessation of menses-the perimenopausal transition-is a risk factor for depressive episodes. ${ }^{19}$ As women age past the perimenopausal period, data fail to demonstrate an increase in rates of major depression disorder following menopause. The primary predictor of depression following menopause is prior depressive history. Women may also be in a caregiving role during this time, which often places extra stressors on life events. Women are at greater risk for psychiatric morbidity than are men at all stages of caregiving. ${ }^{23}$ Adult caregivers report higher levels of depressive symptoms, clinical depression, and anxiety. ${ }^{24-26}$

Over the age of 55, gender differences in depression become less apparent. ${ }^{27}$ Symptom profiles that characterize depression in late life differ from those earlier in the life span, with older adults less likely to endorse dysphoria. A constellation of symptoms more frequent in older adults and older women specifically is depletion syndrome. Its symptoms include loss of interest, loss of energy, hopelessness, helplessness, and psychomotor retardation..$^{28}$ Depletion syndrome or motivation symptom cluster seems more prevalent in elderly women. ${ }^{28}$ Bereavement may more often play a role in this age group as well. A subset of older adults with late-onset depression may represent a type of vascular depression associated with structural brain changes, vascular risk factors, and cognitive impairment. ${ }^{29-31}$ In such cases, the depressive, or "subcortical," disease is presumed to be organic in nature and seems to be chronic and treatment resistant. ${ }^{32}$

Early-onset depression, defined as a depression onset before age 22 years, can be expected to negatively influence educational attainment and the future earning power of young women..$^{33}$ Illness that substantially reduces physical, social, or cognitive functioning is particularly burdensome to young adults in the years immediately after high school. One study showed that a 21-year-old woman with early-onset major depressive disorder could expect future annual earnings that are 12\% to 18\% lower 
than those of a randomly selected 21-year-old woman, whose onset of major depressive disorder occurred after age 21 or not at all. ${ }^{33}$ However, early-onset major depressive disorder did not adversely affect the educational attainment of men.

\section{Ethnic Racial Differences in Prevalence of Depression}

The National Health and Nutrition Examination Survey III findings indicate that prevalence of depression differs significantly by race/ethnicity, but they also indicate that comparative rates depend on the type of depression. ${ }^{34}$ Black Americans and Mexican Americans have higher lifetime prevalence rates of dysthymic disorder $(P<0.05)$, whereas white Americans have higher lifetime prevalence rates of major depressive disorder $(P<0.01$ and $P=0.05$, respectively). Mexican Americans and white Americans have a significantly earlier onset of major depressive disorder than black Americans do $(P=0.001)$. Persons living in poverty had nearly 1.5 times the prevalence of major depressive disorder; however, poverty was significantly associated with prevalence of major depressive disorder only for white respondents $(P=0.023)$. Lack of education was a significant risk factor for dysthymic disorder even after controlling for poverty. ${ }^{34}$

Although black Americans are less likely than white Americans to have a major depressive disorder, when they do, it tends to be more chronic and severe. They are also much less likely to undergo treatment. A survey published by Neighbors et al. included self-reports from 3,570 African Americans, 1,621 black Americans of Caribbean descent, and 891 non-Hispanic white Americans aged 18 and older who were interviewed in 2001 through $2003 .{ }^{35}$ The researchers reported that $10.4 \%$ of African Americans, $12.9 \%$ of Caribbean black Americans, and $17.9 \%$ of non-Hispanic white Americans had major depressive disorder at some point in life. Education and income were not linked to higher or lower risk of major depressive disorder in any of the groups. Previous studies had shown that slightly more than half $(57 \%)$ of adults with major depressive disorder underwent treatment. The Neighbors et al. study showed that the treatment rate was less than half (45\%) for African Americans and less than a quarter (24.3\%) for Caribbean black Americans. ${ }^{35}$

Data suggest that some aspects of culture may protect against depression. More specifically, rates of depression are low among Mexican Americans born in Mexico, and immigrant Mexican American women have an $8 \%$ lifetime rate of depression, which is similar to rates of nonimmigrant Mexicans. However, after 13 years in the United States, rates of depression for Mexican women who immigrated to the United States rise precipitously. Women of Mexican heritage born in the United States experience lifetime rates of depression nearly twice the rate of immigrants and similar to those of white persons in the United States. One possible explanation for these findings is that the difference in cultural social support and cultural values versus those in the United States may be protective in Mexico.

\section{Summary}

Women face a higher risk than men do of developing depression. During adolescence, the prevalence rates of depression in girls increase until they are twice the rate of boys by young adulthood. Throughout a woman's life, depression becomes a more significant risk at different times, such as during the postpartum or the perimenopausal period. Some of these occurrences may be explained by the changing hormonal milieu taking place at those times. Women are also more susceptible to depression after facing physical or sexual abuse, poverty, housing problems, or loss of a close friend. One of the most replicated findings is that a past depressive episode is the best predictor of a future depressive episode. One of the explanations for the higher rate of depression in women is that women have a greater incidence of first depressive episode, which often begins during adolescence or young adulthood. Depression does not discriminate: women of all races are susceptible to depressive episodes.

\section{REFERENCES}

1. Nolen-Hoeksema S. Gender differences in depression. In: Gotlib I, Hammen C, eds. Handbook of Depression. New York, NY: Guilford Press; 2002;492-509.

2. University of Michigan Depression Center. Facts about depression in children and adolescents. Available at: www.med.umich.edu/depression/ caph.htm. Accessed June 3, 2007.

3. Kendler KS. Major depression and generalized anxiety disorder. Same genes (partly) different environments-revisited. Focus. 2004;2:416-25.

4. Foley DL, Neale MC, Gardner CO, Pickles A, Kendler K. Major depression and associated impairment: same or different genetic and environmental risk factors? Am J Psychiatry. 2003;160:2128-33.

5. Kuehner C. Gender differences in unipolar depression: an update of epidemiological findings and possible explanations. Acta Psychiatr Scand. 2003;108:163-74.

6. Kendler K, Thornton L, Prescott C. Gender differences in the rates of exposure to stressful life events and sensitivity to their depressogenic effects. Am J Psychiatry. 2001;158:587-93.

7. Schulz AJ, Gravlee CC, Williams DR, Israel BA, Mentz G, Rowe Z. Discrimination, symptoms of depression, and self-rated health among African American women in Detroit: results from a longitudinal analysis. Am J Public Health. 2006;96:1265-70.

8. Schulz AJ, Israel BA, Zenk SN, et al. Psychosocial stress and social support as mediators of relationships between income, length of residence and depressive symptoms among African American women on Detroit's eastside. Soc Sci Med. 2006;62:510-22.

9. Maciejewski PK, Prigerson HG, Mazure CM. Sex differences in event-related risk for major depression. Psychol Med. 2001;31:593-604.

10. Saunders BE, Kilpatrick DG, Hanson R, Resnick H, Walker ME. Prevalence, case characteristics, and long-term psychological correlates of child rape among women: a national survey. Child Maltreatment. 1999;4:187-200

11. Golding J. Intimate partner violence as a risk factor for mental disorders: a meta-analysis. J Fam Violence. 1999;14:99-132.

12. Springer KW, Sheridan J, Kuo D, Carnes M. Long-term physical and mental health consequences of childhood physical abuse: results from a large population-based sample of men and women. Child Abuse Negl. May 25, 2007;31(5):517-30. Epub ahead of print. 
13. Dube SR, Anda RF, Felitti VJ, Chapman DP, Williamson DF, Giles WH. Childhood abuse, household dysfunction, and the risk of attempted suicide throughout the life span: findings from the Adverse Childhood Experiences Study. JAMA. 2001;286(24):3089-96.

14. Paolucci EO, Genuis ML, Violato C. A meta-analysis of the published research on the effects of child sexual abuse. J Psychol. 2000;135:17-36.

15. Belle D, Doucet J. Poverty, inequality, and discrimination as sources of depression among U.S. women. Psychol. Women Quarterly. 2003;27(2):101-13.

16. Oei TP, Kwon SM. Evaluation of the integrated cognitive model of depression and its specificity in a migrant population. Depress Anxiety. 2007;24:112-23.

17. Heim C, Newport J, Heit S, et al. Pituitary-adrenal and autonomic responses to stress in women after sexual and physical abuse in childhood. JAMA. 2000;284:592-97.

18. Freeman EW, Sammel MD, Lin H, Nelson DB. Associations of hormones and menopausal status with depressed mood in women with no history of depression. Arch Gen Psychiatry. 2006;63:375-82.

19. Freeman EW, Sammel MD, Liu L, Gracia CR, Nelson DB, Hollander L. Hormones and menopausal status as predictors of depression in women in transition to menopause. Arch Gen Psychiatry. 2004;61:62-70.

20. Hendrick V, Altshuler L, Strouse T, Grosser S. Postpartum and nonpostpartum depression: differences in presentation and response to pharmacologic treatment. Depress Anxiety. 2000;11:66-72.

21. Hendrick V, Altshuler L. Management of major depression during pregnancy. Am J Psychiatry. 2002;159:1667-73.

22. Gjerdingen DK, Yawn BP. Postpartum depression screening: importance, methods, barriers, and recommendations for practice. J Am Board Fam Med. 2007;20:280-88

23. Wisner KL, Parry BL, Piontek CM. Clinical practice. Postpartum depression. N Engl J Med. 2002;347:194-99.

24. Schulz R, O'Brien AT, Bookwala J, Fleissner K. Psychiatric and physical morbidity effects of dementia caregiving: prevalence, correlates, and causes. Gerontologist. 1995;35:771-91.
25. Schulz R, Visintainer P, Williamson GM. Psychiatric and physical morbidity effects of caregiving. J Gerontol. 1990;45:181-91.

26. Gatz M, Fiske A. Aging women and depression. Prof Psychol Res Prace. 2003;34:3-9.

27. Gatz M, Fiske A, Reynolds CA, Wetherell JL, Johansson B, Pedersen NL. Sex differences in genetic risk for dementia. Behav Genet. 2003;33:95-105.

28. Newmann J, Engel R, Jensen J. Age differences in depressive symptom experiences. J Gerontol. 1991;46:224-35.

29. Alexopoulos GS, Meyers BS, Young RC, Campbell S, Silbersweig D, Charlson M. "Vascular depression" hypothesis. Arch Gen Psychiatry. 1997;54:915-22.

30. Alexopoulos GS, Meyers BS, Young RC, Kakuma T, Silbersweig D, Charlson M. Clinically defined vascular depression. Am J Psychiatry. 1997;154:562-65.

31. Hickie I, Scott E. Late-onset depressive disorders: a preventable variant of cerebrovascular disease? Psychol Med. 1998;28:1007-13.

32. Simpson S, Baldwin RC, Jackson A, Burns AS. Is subcortical disease associated with a poor response to antidepressants? Neurological, neuropsychological and neuroradiological findings in late-life depression. Psychol Med. 1998;28:1015-26.

33. Berndt ER, Koran LM, Finkelstein SN, et al. Lost human capital from early-onset chronic depression. Am J Psychiatry. 2000;157:940-47.

34. Riolo SA, Nguyen AT, Greden JF, King CA. Prevalence of depression by race/ethnicity: findings from the National Health and Nutrition Examination Survey III. Am J Public Health. 2005;95:998-1000.

35. Neighbors HW, Caldwell C, Williams DR, et al. Race, ethnicity, and the use of services for mental disorders: results from the National Survey of American Life. Arch Gen Psychiatry. 2007;64:485-94. 